\title{
Organizational Commitment and Employee Performance with Special Reference to Administrative Officers at the University of Jaffna, Sri Lanka
}

\section{P. Krishnanathan: Asst.Registrar, Vavuniya Campus of the University of Jaffna, Sri Lanka.}

-T. Mangaleswaran: Senior Lecturer, Vavuniya Campus of the Univerity of Jaffna, Sri Lanka.

\begin{abstract}
An empirical knowledge gap has been observed regarding the relationship between organizational commitment and employee job performance of Administrative Officers in University of Jaffna, Sri Lanka. Therefore, in order to fill this empirical knowledge gap, this study was carried out with the objectives of explores the relationship between organizational commitment and job performance and explores the impact of organizational commitment on job performance of Administrative Officers in University of Jaffna, Sri Lanka. The data of this study have been collected from 40 Administrative Officers in University of Jaffna, Sri Lanka through the structured questionnaire. The data were analysed with univariate and bivariate analyses using SPSS 19.0. Findings of the study stated that there is a medium positive relationship between organizational commitment and job performance. And also findings of the study stated that organizational commitment has significant impact on employee performance. This study suggested that organizational commitment of the employees can improve employees" job performance.
\end{abstract}

Key words: Organizational commitment, Job performance, Employee.

Recent days, organizations continuously focus on enhancing the organizational performance in order to gain the competitive advantage. In this sense, several researchers revealed that, employees are the significant actors in determining the organizational performance (Brío, Fernandez, \& Junquera, 2007; Jabbour \& Santos, 2008). Organizational success depends on the hands of the employees who put in their best efforts to be effective in their areas of work. Hence, organizations turns their spot light on enhancing the employees" attitudes and behavior to enrich the individual employee performance which in turns leads to improve the organizational performance.

In this scenario, organizational commitment of employee considered as an important attitude in the organizational context. Commitment is employee psychological attachment to the organization (Meyer \& Allen, 1991). Every employee of an organization needs to give his/her best performance, along with highest commitment to organization goals its success in long term. The success of the organization depends on the employees" ability and their commitment. Employee organizational commitment is a significant psychological behavior. Committed employee performance is in higher level than the non-committed employee performance. Highly committed employee is a true member of the organization. Employee high level of commitment leads to several favorable organization outcomes such as, high productivity, enhance organization goodwill, high

International Journal of

2018

DOI: 10.53935/2641-533x.v1i3.85

Corresponding Author: T. Mangaleswara Funding: This study received no specific financial support.

Received: 13 July 2018

Revised: 15 October 2018

Accepted. 5 December 2018

() 2018 by the authors; licensee Academic

Publishing Group 
profit, less turnover, less absenteeism, provide promotional opportunities and training opportunities, enhance employee empowerment and job security.

Thus, most of the organizations give great importance to increase employee commitment to enhance the organizational performance. In this context, number of scholars contributed to the understandings of importance of organizational commitment (Meyer \& Allen, 1991; Randall, 1993; Rhoades, Eisenberger, \& Armeli, 2001; Shen \& Jiuhua, 2011). However, In Sri Lankan context, only few studies have focus on the relationship between commitment and employee job performance. Thus, there is an empirical research gap exist regarding the relationship between commitment and employee job performance.

In this study main problem is that whether "performance of employees is determined by the employees" commitment to an organization". Success of the organization depends on the performance of the employees. Organizational commitment is an important concept in an organization to increase the performance of employees. If employees did not have commitment on their organization they will only work for the monetary benefits. Organizational commitment plays an important role on the performance of employees. In considering above reasons, the researchers would like to conduct this research study in order to fill the empirical knowledge gaps with regards to relationship between organizational commitment and organizational performance. Hence, the objectives of this study are to identify the impact of organizational commitment on employee performance, identify the relationship between organizational commitment and the employee performance with the administrative officers attached to the University of Jaffna, Sri Lanka.

\section{Literature Review}

\subsection{Definitions of Organizational Commitment}

Organizational commitment considered as a crucial job related attitude of employees which plays a major role in determining the employee performance. Many organizational behaviour researchers have contributed extensively to the development of the OC literature by providing many nuanced OC definitions. They are as follows: Organizational Commitment can be defined as the relative strength of an individual"s identification with and involvement in a particular organization (Porter \& Smith, 1970). Sheldon (1971) defined Organizational Commitment as an attitude or orientation towards the Organization which links or attached the identity of the person to the organization. According to Mowday., Steers, and Porter (1979). Commitment has been defined as having a strong belief in an organization,,s value and goals. Such that a person desires to maintain a part of the organization and is willing to expand considerable effort for the organization.

\subsection{Relationship between Organizational Commitment and Employee Performance}

Success of the organization depends on the performance of the employees. Thus, organizations increasingly required to focus on improving the employees" job related attitudes and behaviors to enhance the employee performance. In this context, several researchers revealed the importance of organizational commitment to improve the employees" job performance. The study of employees" job performance and organizational commitment is of primary importance to the top-level Management of the organization. Somers and Birnbaum (1998) studied the relationship of Career Commitment to performance effectiveness and resulted in a positive relationship. Commitment of employees can be an important instrument for improving the performance of the organization. Meyer and Allen (1991) have revealed that organizational commitment is important because high levels of Commitment lead to several favorable organizational outcomes. It reflects the extent to which employees" identity with an organization and is committed to its goals. Dordevic (2004) stated that the commitment of employee is an important issue because it may be used to predict employees" performance, absenteeism and other behaviours. High level of commitment provides secure and stable work force and provide Competitive advantage to the organization (Steers, 1977). Further, highly committed employees were found to have a higher intent to remain with the organization, a stronger desire to attend work and more positive attitude about their employment (Steers, 1977).

According to Dansereau, Graen, and Haga (1975) better employee performance was correlated with more role, clarity, higher satisfaction and stronger organizational commitment. In general, organizational commitment is considered a useful measure of organizational effectiveness (Mowday, Porter, \& Dubin, 1974). Morrow (1993) stated that organizational commitment has the potential to predict organizational outcomes

Vol. 1, No. 3, pp. 168-173

Received: 13 July 2018

Revised: 15 October 2018

Accepted: 5 December 2018

December 2018

Publishing Group

| 169 
such employee job performance, turnover, absenteeism, tenure and organizational goals. In addition to that, Kinicki and Vecchio (1994) explained that organizational commitment is leading to achieve the desired organizational success or outcomes. According to the above literature, this review establishes that organizational commitment has a positive relationship with employee job performance as a hypothesis of this review:

Hypothesis: There is a positive relationship between organizational commitment and employee performance.

\section{Conceptual Framework of the Study}

Based on the above literature review, following conceptual model was developed by researcher to carry out this research.

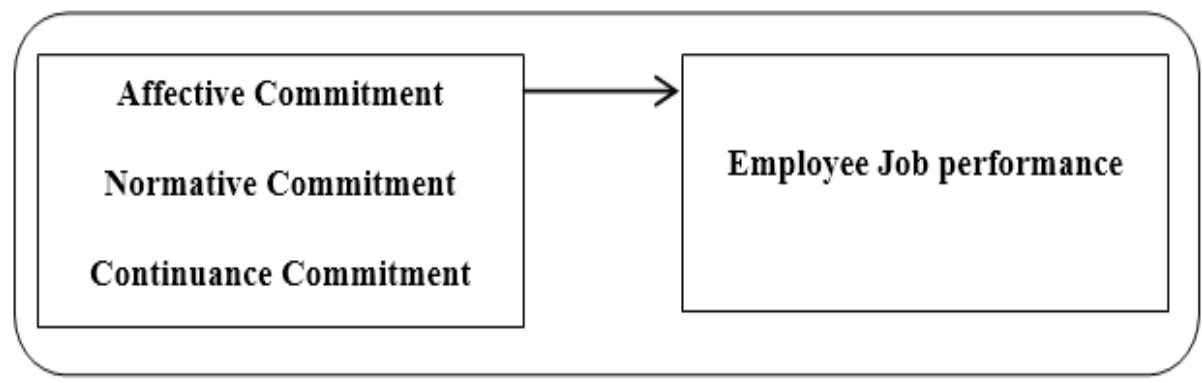

Figure-1. Conceptual framework

\section{Methodology}

\subsection{Data Collection Methods}

The total population for the study was 40 administrative officers in the University of Jaffna, Sri Lanka. The total population considered as the sample to conduct this study. Data collection plays a vital role in any research. The current study used primary and secondary data. The primary data of this study were collected from the respondents through structured questionnaire. The questionnaire contained questions relating to organizational commitment and employee job performance. Further, researchers also employed interview and discussion method to collect the primary data. Secondary data collected through journals, magazines and University publications.

\subsection{Data Analysis Techniques}

Correlation analysis was conducted to examine the relationship between the variables. According to Sekaran (2000) the correlation coefficient value (r) range from 0.10 to 0.29 is considered as weak, from 0.30 to 0.49 is considered as medium and from 0.50 to 1.0 is considered as strong. However, according to Field (2005) correlation coefficient should not go beyond 0.8 to avoid multi-collinearity. The correlation analysis shows that multio- collinearity does not threaten the validity of the data.

Simple Linear Regression was used to measure the impact of the independent variable on a dependent variable. The regression coefficient (represent by R2) can take on any value between 0 and 1 . It measures how much the dependent variable varies with an independent variable when all other independent variables are held constant. Therefore, simple linear regression was used to measure the impact of organizational commitment on employee job performance.

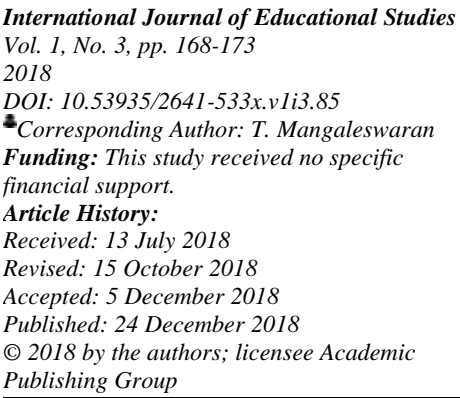

\begin{tabular}{llll}
\multicolumn{3}{c}{ Table-1. Descriptive Statistics. } \\
\hline Variables & Mean & SD \\
\hline 1 & Affective Commitment & 3.33 & 0.38 \\
2 & Normative Commitment & 3.60 & 0.8 \\
3 & Continuance Commitment & 3.81 & 0.60 \\
4 & Employee Job performance & 4.53 & 0.37 \\
\hline Source: Survey data.
\end{tabular}




\section{Findings of the Study}

\subsection{Descriptive Statistic of Variables}

Table 1 shows the mean values and standard deviations of independent and dependent variable. Affective commitment, normative commitment and continuance commitment were the independent variables and the performance was the dependent variable. Continuance commitment indicates that the higher mean value 3.81 than the affective commitment, normative commitment 3.333 and 3.60. The administrative staffs of the University of Jaffna continuously committed to their work in achieving organizational goals and objectives with involving the emotional attachment with an involvement in the organization than the normative commitment. The dependent variable displays the higher mean value than the independent variable 4.53 . The findings of the study revealed that there is a high level of organizational commitment exists among the administrative staff of the University of Jaffna, Sri Lanka. The results also imply that job performance of administrative staff is in high level.

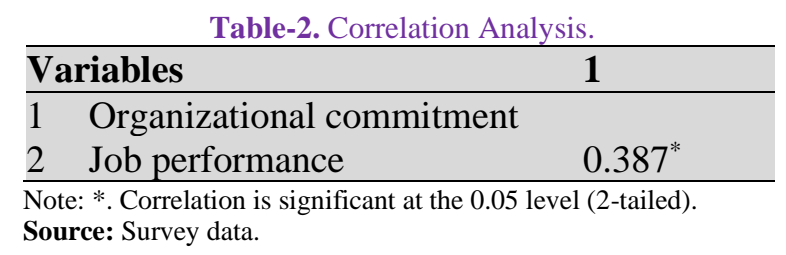

\subsection{Correlation Analysis}

Table 2 present the correlation analysis of the study. Correlation analysis explained that organizational commitment has a medium positive correlation with job performance.

Table-3. Model Summary of Impact of Organizational Commitment on Job Performance.

\begin{tabular}{|c|c|c|}
\hline Model R & R Square & Adjusted R Square Std. Error of the Estimate \\
\hline $0.387^{\mathrm{a}}$ & 0.150 & 0.56773 \\
\hline
\end{tabular}

\subsection{Simple Linear Regression Analysis}

Table 3 shows the model summary of simple linear regression analysis. Adjusted R square is 0.410. Therefore Researcher can conclude that $15 \%$ of variability in job performance is accounted by the organizational commitment. In other words, $85 \%$ of variance of job performance was affected by other variables.

Table-4. Coefficients of Organizational Commitment and Job performance.

\begin{tabular}{|c|c|c|c|c|c|c|}
\hline \multirow[b]{2}{*}{ Model } & & \multicolumn{2}{|c|}{$\begin{array}{l}\text { Unstandardized } \\
\text { Coefficients }\end{array}$} & \multicolumn{2}{|l|}{$\begin{array}{l}\text { Standardized } \\
\text { Coefficients }\end{array}$} & \multirow[b]{2}{*}{ Sig. } \\
\hline & & B & Std. Error & Beta & $\mathbf{t}$ & \\
\hline \multirow[t]{2}{*}{1} & (Constant) & 2.835 & 0.436 & & 6.497 & 0.000 \\
\hline & $\begin{array}{l}\text { Organizational } \\
\text { Commitment }\end{array}$ & 0.271 & 0.118 & 0.387 & 2.300 & 0.029 \\
\hline
\end{tabular}

a. Dependent Variable: Performance. Source: Survey Data.

International Journal of Educational Studies Vol. 1, No. 3, pp. 168-173

2018

DOI: $10.53935 / 2641-533 x . v 1 i 3.85$

Corresponding Author: T. Mangaleswaran Funding: This study received no specific financial support.

Article History:

Received: 13 July 2018

Revised: 15 October 2018

Accepted: 5 December 2018

Published: 24 December 2018

(C) 2018 by the authors; licensee Academic Publishing Group
The regression analysis in Table 4 indicates that the organizational commitment has significant impact on performance with $\mathrm{t}$-statistic 2.300 and significant level is 0.029 , which is less than p-value of 0.05 and Beta value of organizational commitment 0.271 . Thus $\mathrm{H}_{1}$ supports that organizational commitment has positive impact on job performance. Therefore, the hypothesis 1 is accepted in this study and the null hypothesis is rejected.

\section{Conclusion of the Study}

This research study concluded that there is a positive relationship between organizational commitment and 
employee performance. High level of organizational commitment is linked to higher level of job performance. Therefore we assume that organizational commitment is positively related with organizational performance and job satisfaction.

At the same time, other factor also influence on performance. Finding of the current study clearly suggest that organizational commitment impact on the performance of employees. Employees who are committed to their respective institution are more likely not only to remain with the institution but are also likely to exert more effort on the behalf of the organization and work toward its success. Hence, organizations increasingly required to pay a great attention on improving the organizational commitment of employees to enrich their job performance.

This study has some implications for academics and practitioners. For academic research, this study contributes to understand the relationship between organizational commitment and job performance. The results of the study also have useful implications for organizations which want to improve the employees" job performance. Organizations that want to enhance the employees" job performance may need to enhance the organizational commitment of all employees.

\section{Recommendations of the Study}

The following recommendations are made on the basis of the present study. Employees are mostly increasing their performance for receiving higher salary or other carrier improvement advantages. Administrative officers are ready to leave the present job, once they received better job than the present job. It is natural. This attitude will negatively impact the effectiveness of the Government sector. Organizations can eliminate this type of turnover intention of employees through improving the organizational commitment of employees. University administrators should take more consideration to increase the organizational commitment. For it they can follow the following guidelines.

1. Administrators should be treated fairly manner and two ways communication should be followed in the University.

2. The University should support the development of the Administrative Officers.

3. The University should give challenging job to the Administrative Officers.

\section{Limitations of the Study}

This study has a series of limitations. First, the current study is carried out based on the information collected only from the Administrative officers of the University of Jaffna, Sri Lanka. Second, data were collected at one point of time, applying a cross sectional design. Third, sample size $(n=40)$ of the study is limited. Fourth, this study is mainly conducted based on the data collection through the questionnaire and antecedent variables are not taken into consideration. Finally, this study did not consider the impact of control variables (e.g. sample profiles or other variables) on organizational commitment. Finally, there is also limited generalization of the findings of this study beyond the current organization where this study conducted. Future researchers should focus on these limitations in enriching knowledge in these areas.

\section{References}

Brío, J. Á., Fernandez, E., \& Junquera, B. (2007). Management and employee involvement in achieving an environmental action-based competitive advantage: An empirical study. The International Journal of Human Resource Management, 18(4), 491522.Available at: http://dx.doi.org/10.1080/09585190601178687.

Dansereau, J. F., Graen, G., \& Haga, W. J. (1975). A vertical dyad linkage approach to leadership within formal organizations: A longitudinal investigation of the role making process. Organizational Behavior and Human Performance, 13(1), 4678.Available at: https://doi.org/10.1016/0030-5073(75)90005-7.

Dordevic, B. (2004). Employee commitment in times of radical organisational changes. Economics and Organisation, 2(2), 111-117.

Field, A. (2005). Discovering statistics using SPSS (2nd ed.). London: Sage Publication.

Jabbour, C. J. C., \& Santos, F. C. A. (2008). Relationships between human resource dimensions and environmental management in companies: proposal of a model. Journal of Cleaner Production, 16(1), 51-58.Available at: http://doi.org/10.1016/j.jclepro.2006.07.025

Kinicki, A. J., \& Vecchio, R. P. (1994). Influences on the quality of supervisor-subordinate relations: The role of time-pressure, organizational commitment, and locus of control. Journal of Organizational Behavior, 15(1), 75-82.Available at: https://doi.org/10.1002/job.4030150108.

Meyer, J. P., \& Allen, N. J. (1991). A three-component conceptualization of organizational commitment. Human Resource Management Review, 1(1), 61-89.Available at: https://doi.org/10.1016/1053-4822(91)90011-z.

Morrow, P. C. (1993). The theory and measurement of work commitment. Greenwich, CT: Jai Press Inc. 
Mowday, R. T., Porter, L. W., \& Dubin, R. (1974). Unit performance, situational factors, and employee attitudes in spatially separated work units. Organizational Behavior and Human Performance, 12(2), 231-248.Available at: https://doi.org/10.1016/00305073(74)90048-8

Mowday., R. T., Steers, R. M., \& Porter, L. W. (1979). The measurement of organizational commitment. Journal of Vocational Behavior, 14(2), 224-247.

Porter, L. W., \& Smith, F. E. (1970). The etiology of organizational commitment: A longitudinal study of the initial stages of employee-organization reactions. Unpublished Manuscript, University of California, Irvine.

Randall, D. M. (1993). Cross-cultural research on organizational commitment: A review and application of hofstedees value survey module. Journal of Business Research, 26(1), 91-110.Available at: https://doi.org/10.1016/0148-2963(93)90045-q.

Rhoades, L., Eisenberger, R., \& Armeli, S. (2001). Affective commitment to the organization: The contribution of perceived organizational support. Journal of Applied Psychology, 86(5), 825-836.

Sekaran, U. (2000). Research methods for business: A skill building approach (3rd ed.). New York: John Willey \& Sons.

Sheldon, M. E. (1971). Investments and involvements as mechanisms producing commitment to the organization. Administrative Science Quarterly, 16(2), 143-150.Available at: https://doi.org/10.2307/2391824.

Shen, J., \& Jiuhua, Z. C. (2011). Effects of socially responsible human resource management on employee organizational commitment. The International Journal of Human Resource Management, 22(15), 3020-3035.Available at: https://doi.org/10.1080/09585192.2011.599951.

Somers, M. J., \& Birnbaum, D. (1998). Work-related commitment and job performance: It's also the nature of the performance that counts. Journal of Organizational Behavior: The International Journal of Industrial, Occupational and Organizational Psychology and Behavior, 19(6), 621-634.Available at: https://doi.org/10.1002/(sici)1099-1379(1998110)19:6\%3C621::aidjob853\%3E3.0.co;2-b.

Steers, R. (1977). Antecedents and outcomes of organizational commitment. Administrative Science Quarterly, 22(1), 46-56.Available at: https://doi.org/10.2307/2391745.

International Journal of Educational Studies Vol. 1, No. 3, pp. 168-173

2018

DOI: 10.53935/2641-533x.v1i3.85

- Corresponding Author: T. Mangaleswaran

Funding: This study received no specific

financial support.

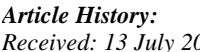

Received: 13 July 2018

Revised: 15 October 2018

Accepted: 5 December 2018

Published: 24 December 2018

(C) 2018 by the authors; licensee Academic

Publishing Group 